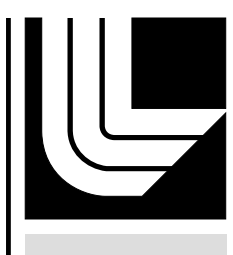

LAWRENCE LIVERMORE N A T IO N A L LABORATORY

Metal Angle Correction in the Cylinder Test

P. C. Souers, R. Garza, H. Hornig, L. Lauderbach, C. Owens, P. Vitello

September 15, 2010 
This document was prepared as an account of work sponsored by an agency of the United States government. Neither the United States government nor Lawrence Livermore National Security, LLC, nor any of their employees makes any warranty, expressed or implied, or assumes any legal liability or responsibility for the accuracy, completeness, or usefulness of any information, apparatus, product, or process disclosed, or represents that its use would not infringe privately owned rights. Reference herein to any specific commercial product, process, or service by trade name, trademark, manufacturer, or otherwise does not necessarily constitute or imply its endorsement, recommendation, or favoring by the United States government or Lawrence Livermore National Security, LLC. The views and opinions of authors expressed herein do not necessarily state or reflect those of the United States government or Lawrence Livermore National Security, LLC, and shall not be used for advertising or product endorsement purposes.

This work performed under the auspices of the U.S. Department of Energy by Lawrence Livermore National Laboratory under Contract DE-AC52-07NA27344. 


\title{
Metal Angle Correction in the Cylinder Test
}

\author{
P. C. Souers*, Raul Garza, Howard Hornig, Lisa Lauderbach, Cinda Owens and Peter Vitello \\ Energetic Materials Center, Lawrence Livermore National Laboratory, Livermore, CA USA 94550 \\ Corresponding Author; e-mail; souers1@1lnl.gov
}

\begin{abstract}
Cylinder test data shows that the copper wall angle increases with time in a given shot and becomes much larger if the wall is at half-thickness. The true velocity is suggested to be that perpendicular to the wall, and this brings full and half-wall data in closer agreement. The previously published Gurneytype equation for calculating the detonation energy density at each relative volume is modified by the angle of the wall and the angle of the measuring probe. This provides a unique solution to the energy density that does not require empirical coefficients or standards. We derive the length of the cone perpendicular to the cylinder surface and we use this as a description of the constant relative volume, creating a unified model for the first time. As a standard for full-wall cylinders, we obtain relative volumes of 2.43, 4.50 and 7.12 at the scaled wall displacements of 6, 12.5 and $19 \mathrm{~mm}$. For a full-wall copper cylinder at the three points, the wall angles average 10.0, 11.0 and 11.6 degrees. Besides Cylinder test data on copper, previously unpublished framing camera pictures also measure angles for eight different metals. The angles are a function of wall thickness and relative volume but of nothing else, including the type of metal. For modeling, our simulation code calculates the wall velocity as seen along a particular probe direction, as this is a more realistic comparison to measurements than a zone particle velocity.
\end{abstract}

Keywords: Cylinder test, detonation, detonation energy, adiabat energy, Gurney model

\section{Introduction}

An empirical Equation of State used in a computer code needs to be calibrated to the detonation energy densities at various volumes of the gas product adiabat expansion. The Cylinder test is perhaps the only way to measure these energy densities [1-4]. An annealed copper cylinder containing explosive is detonated at one end and the velocity of the expanding metal wall measured. One way to get the adiabat energies is to fit a cylinder model with the hydrocode many times, but this is so time intensive that it is rarely done. A practical alternative is the Cylinder test, which generate JWL equations-of-state that give the right answer when inserted into a hydrocode.

A schematic of the expanded cylinder wall is shown in Figure 1. The bottom horizontal line is the cylinder axis with detonation moving left to right. The vertical line is the inner radius $\mathrm{R}$ in gray and the outer radius $\mathrm{R}+\mathrm{x}$ in black. The black vertical vector as well represents the vector $\mathrm{u}_{\mathrm{m}}$, which is the outside wall velocity at $0^{\circ} . \Theta$ is the angle of the wall to the axis in this section of cylinder. Experimental observations are made at the angle $\alpha$ giving the vector $u_{\mathrm{a}}$. For the streak camera, the angle $\alpha$, is zero but it is non-zero for the Fabry or heterodyne velocimetry. 
From the beginning, the wall velocities at the scaled displacements of

$$
D=\frac{(R+x)-\left(R_{o}+x_{o}\right)}{n}=6,12.5 \text { and } 19 \mathrm{~mm}
$$

were taken as the "official" markers of performance. Above, $\mathrm{R}_{\mathrm{O}}$ and $\mathrm{x}_{\mathrm{O}}$ are the initial explosive radius and wall thickness, and $\mathrm{R}$ and $\mathrm{x}$ are the same at a later time. "Scaled" means reduced to a $12.7 \mathrm{~mm}$-radius (1inch dia.) by adjusting distance and time with radius using $\mathrm{n}$, but not velocity. The scaling parameter $\mathrm{n}$ is equal to $\mathrm{R}_{\mathrm{o}} / 12.7$. The advantage of scaled data is that all Cylinder tests may be directly compared, no matter what their size or wall material. In the early days [1-3], the streak wall velocity was assumed proportional to the detonation energy density. In order to convert, $1.765 \mathrm{~g} / \mathrm{cm}^{3}$ PETN was used as a standard and the cylinder was run in the codes many times to set the energies. Then, we turned to the 1943 Gurney pipe bomb model [4-6], which is a cylinder in which the explosive all detonates at once, so that the expansion is all-radial, but the walls stay at constant thickness. However, we added a feature that allows the walls to thin as they expand. The wall movement displacements are then related to relative volumes, which have been 2.2, 4.4, and 7.2 at the three scaled displacements listed in Eq. (1). The resulting JWL's constructed from these three points work must in hydrocodes, which is the ultimate justification.

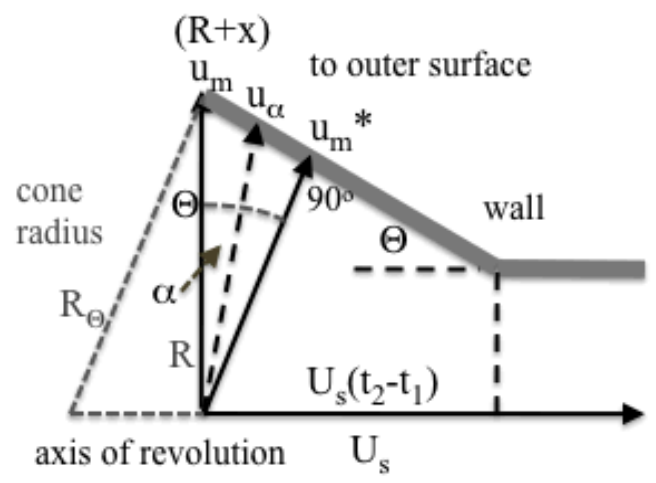

Figure 1. Schematic of the cylinder wall. The vector $\mathrm{u}_{\mathrm{m}}{ }^{*}$ is perpendicular to the expanding wall.

The original inner radius is $R_{0}$ and the wall thickness $x_{0}$, so that the original outer radius is $R_{0}+x_{0}$. At later times, we measure $\mathrm{R}+\mathrm{x}$. Assuming constant density in the metal wall, mass conservation leads to the equation

$$
(R+x)^{2}-R^{2}=\left(R_{o}+x_{o}\right)^{2}-R_{o}^{2} .
$$

We solve for the inner radius $\mathrm{R}$ to get 


$$
R=\left\{(R+x)^{2}+R_{o}^{2}-\left(R_{o}+x_{o}\right)^{2}\right\}^{1 / 2} .
$$

The three wall velocities were converted into three detonation energy densities, $\mathrm{E}_{\mathrm{d}}$, using this Gurneytype $[5,6]$ equation at each relative volume [4]:

$$
E_{d}=\delta\left\{\rho_{m}\left(\frac{R+x}{R_{o}}\right)^{2} \ln \left(\frac{R+x}{R}\right)+\frac{\rho_{o}}{4}\left(\frac{R+x}{R}\right)^{2}\right\} u_{m}{ }^{2}
$$

where $\delta$ was used for adjustment. Also, $\rho_{\mathrm{m}}$ is the initial metal density, and $\rho_{\mathrm{o}}$ the initial explosive density.

Two kinds of cylinders were used over 45 years at LLNL. The "full-wall" cylinder has a wall thickness $1 / 5^{\text {th }}$ the radius, and this is the current standard everywhere, usually with a $12.7 \mathrm{~mm}$ radius. For many years the "half-wall" cylinder, with a wall thickness $1 / 10^{\text {th }}$ the radius and most with a 25.4 mm radius, was used to get a higher wall velocity and, hence, more resolution. The transition from streak camera to lasers made this expensive version obsolete. The half-wall shots left a legacy of trouble, because the half-wall energy densities were always several percent higher than the full-wall. Table 1 in the "No Wall Correction" shows the half-wall-to-full-wall multiplier for cylinders of the same radius measured with streak camera. There are few such pairs because usually there were radius differences. This effect did not appear to be caused by work-hardening, because it appeared regardless of energy, and so an empirical adjustment was used to bring the half-wall data into line.

Table 1. Multiplier for conversion of half-wall to full-wall energy densities at three Cylinder displacements in $\mathrm{mm}$. The new calculation closes the gap partially.

\begin{tabular}{|l|c|c|c|c|c|c|c|c|}
\hline & Density, & $\mathrm{R}_{\mathrm{o}}$, & \multicolumn{3}{c|}{ No Wall Correction } & \multicolumn{3}{c|}{ New Calculation } \\
\cline { 5 - 10 } & $\mathrm{g} \mathrm{cc}^{-1}$ & $\mathrm{~mm}$ & $6 \mathrm{~mm}$ & 12.5 & 19 & $6 \mathrm{~mm}$ & 12.5 & 19 \\
\hline LX-14 & $1.82-1.83$ & 12.7 & 0.986 & 0.958 & 0.961 & 0.997 & 0.972 & 0.975 \\
\hline LX-17 & $1.88-1.91$ & 25.4 & 0.978 & 0.972 & 0.959 & 0.996 & 0.991 & 0.974 \\
\hline PBX 9502 & 1.89 & 25.4 & 1.014 & 0.975 & 0.970 & 1.024 & 0.987 & 0.983 \\
\hline PETN & 1.765 & 12.7 & 1.006 & 0.980 & 0.957 & 1.003 & 0.995 & 0.975 \\
\hline PETN & 1.50 & 12.7 & 0.983 & 0.986 & 0.998 & 0.994 & 0.999 & 1.011 \\
\hline PETN & 1.27 & 12.7 & 1.000 & 0.972 & 0.992 & 1.009 & 0.983 & 1.004 \\
\hline Average & & & 0.994 & 0.974 & 0.973 & 1.004 & 0.988 & 0.987 \\
\hline
\end{tabular}

The second problem came with the modern laser measurements of wall velocity, first with Fabry interferometry and presently heterodyne velocimetry (called "PDV")[7]. The streak camera energy was always high compared to the Fabry result as summarized in Table 2 with five half-wall shots where both methods were used. The Fabry was always set at $7^{\circ}$ to the wall whereas the streak camera looked in at $0^{\circ}$. 
A simple angle correction factor was used to adjust Fabry results to the streak camera, which was considered the standard $[4,8]$.

Table 2. Comparison of the Fabry-to-streak camera detonation energy densities on shots where both were measured. The three Cylinder displacements in $\mathrm{mm}$ are listed.

\begin{tabular}{|l|c|l|l|c|c|c|c|}
\hline & density & & & \multicolumn{2}{c|}{ wall } & \multicolumn{2}{c|}{ Det Energy Ratio, Fabry- } \\
\hline & $\rho_{\mathrm{o}}$ & Shot & detvel & $\mathrm{x}_{\mathrm{o}}$ & \multicolumn{3}{|c|}{ to-Streak } \\
\cline { 9 - 11 } & $\mathrm{g} \mathrm{cc}^{-1}$ & $\mathrm{No}$ & ${\mathrm{mm} \mu \mathrm{s}^{-1}}$ & $\mathrm{~mm}$ & $6 \mathrm{~mm}$ & 12.5 & 19 \\
\hline Explosive & 1.942 & 564 & 9.210 & 1.357 & 0.935 & 0.938 & 0.936 \\
\hline LX-19 (RX-39-AA) & 1.869 & 547 & 8.486 & 2.708 & 0.943 & 0.924 & 0.933 \\
\hline PETN & 1.766 & 586 & 8.283 & 1.367 & 0.981 & 0.946 & 0.933 \\
\hline RX-41-AB (K-6) & 1.857 & 560 & 8.814 & 1.360 & 0.955 & 0.945 & 0.932 \\
\hline RX-52-AE (TATB) & 1.780 & 585 & 7.570 & 2.717 & 0.949 & 0.949 & 0.941 \\
\hline Overall Average & & & & & 0.952 & 0.940 & 0.935 \\
\hline
\end{tabular}

\section{New Considerations}

The cylinder fans out into a cone as the explosive progressively pushes the wall. Figure 2 shows a framing camera picture of a $150 \mathrm{~mm}$-long nickel cylinder, and the expanding sides look straight. In fact, there is a slight bend and the angle $\Theta$ increases with time. The laborious way to get this angle from the data is to use

$$
\Theta=\tan ^{-1}\left\{\frac{(R+x)_{2}-(R+x)_{1}}{U_{s}\left(t_{2}-t_{1}\right)}\right\},
$$

where $U_{\mathrm{s}}$ is the steady state detonation velocity and $t_{2}-t_{1}$ is a time interval in the data.

An easier way of getting $\Theta$ is to consider the velocity vectors in Figure 1, all of which we can measure. In the two right triangles, we have

$$
\begin{aligned}
& \cos (\Theta-\alpha)=\frac{u_{m}^{*}}{u_{\alpha}} \\
& \sin \Theta=\frac{u_{m}^{*}}{U_{s}}
\end{aligned}
$$


where $u_{\alpha}$ is the measured wall velocity for streak camera measurements and $u_{m} *$ is the wall velocity perpendicular to the outside surface. We eliminate $\mathrm{u}_{\mathrm{m}}{ }^{*}$ to get at $0^{\circ}$

$$
\frac{u_{m}}{U_{s}}=\tan \Theta .
$$

Fabry and heterodyne experiments measure the particle velocity along the direction of the laser. Assuming that the particle velocity can be approximated by $\mathrm{u}_{\mathrm{m}}{ }^{*}$, we define this velocity as

$$
u_{f}=u_{m}^{*} \cos (\Theta-\alpha)=U_{s} \sin \Theta \cos (\Theta-\alpha) \text {. }
$$

We checked the substitution of Eqs. (7) and (8) instead of Eq. (5). We found that Fabry or heterodyne data, with a gap of 20 data points in the derivitive for smoothing, gave agreement to with in $\pm 0.2 \%$. However, streak data, which has many fewer points, agrees to within $\pm 2 \%$.

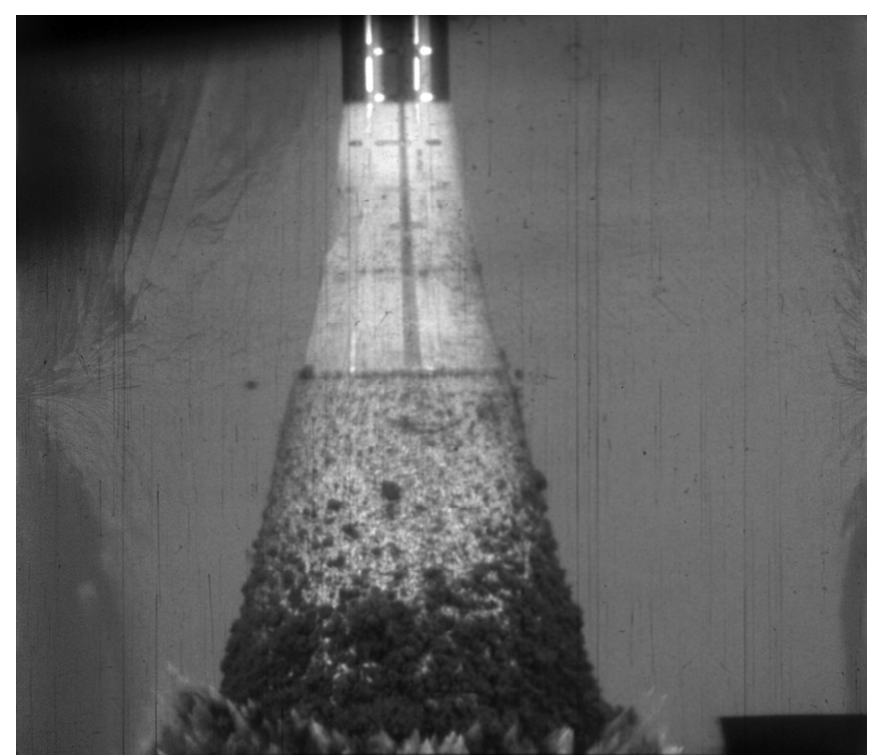

Figure 2. Framing camera picture of detonating LX-04 in a $150 \mathrm{~mm}$-long nickel cylinder. The detonation moves upward, leaving a fan of expanding metal behind. The gas products are beginning to come out of the bottom. The expanding sides look straight but they are slightly curved.

The other part of the Cylinder test recipe is coming up with the relative volume that goes with a given wall displacement, and these are listed in Table 3. A consistent approach is to use relative volumes are based on the geometric relative volume, $\mathrm{v}_{\mathrm{g}}$, which is defined as 


$$
v_{g}=\frac{\pi R^{2}}{\pi R_{o}^{2}}=\frac{(R+x)^{2}+R_{o}^{2}-\left(R_{o}+x_{o}\right)^{2}}{R_{o}^{2}} .
$$

In effect, this volume is a thin wafer along $\mathrm{R}$ in Figure 1. A problem is that $\mathrm{v}_{\mathrm{g}}$ varies between full-wall and half-wall tubes, but no one wanted to keep two sets of values.

Table 3. Different types of relative volumes plus measured angles $\Theta$ at the three Cylinder displacements in $\mathrm{mm}$.

\begin{tabular}{|c|c|c|c|c|}
\hline \multicolumn{2}{|c|}{ Relative Volumes at } & $6 \mathrm{~mm}$ & 12.5 & 19 \\
\hline \multicolumn{2}{|c|}{ both sizes to 1998} & 2.2 & 4.1 & 6.5 \\
\hline \multicolumn{2}{|c|}{ both sizes to 2009} & 2.2 & 4.4 & 7.2 \\
\hline \multicolumn{2}{|c|}{ geometric full wall } & 2.36 & 4.33 & 6.83 \\
\hline \multicolumn{2}{|c|}{ geometric half wall } & 2.26 & 4.13 & 6.53 \\
\hline \multicolumn{2}{|c|}{ cone full wall } & 2.4 & 4.4 & 7.0 \\
\hline \multicolumn{2}{|c|}{ cone half wall } & 2.3 & 4.3 & 6.8 \\
\hline \multicolumn{5}{|c|}{ Cylinder test angle $\Theta$ in copper, degrees, at } \\
\hline \multirow[t]{2}{*}{ full wall } & & 10.0 & 11.0 & 11.6 \\
\hline & stdev & 0.8 & 1.4 & 1.2 \\
\hline \multirow[t]{2}{*}{ half wall } & & 13.3 & 14.4 & 14.9 \\
\hline & stdev & 0.8 & 0.9 & 0.9 \\
\hline
\end{tabular}

Another volume estimate, running along $\mathrm{R}_{\Theta}$ in Figure 1, extends the perpendicular from the wall back to form a cone, which becomes longer as the wall expands. We define a cone geometric volume, $\mathrm{v}_{\mathfrak{c}}$, equal to

$$
v_{c}=\frac{\pi R R_{\Theta}}{\pi R_{o}^{2}}=\frac{(R+x)^{2}+R_{o}^{2}-\left(R_{o}+x_{o}\right)^{2}}{R_{o}^{2} \cos \Theta} .
$$

The tilted $\mathrm{R} / \cos \Theta$ is the "cone radius", which we shall use later. The problem with this version is that it varies with $\Theta$, which requires us to calculate the entire Cylinder test library with 275 full wall entries and 53 half-wall. The results are listed in Table 3, along with the measured angles. This definition of relative volume closes most of the gap between full and half-wall. The angles for each type show no trend with detonation energy density or detonation velocity. We shall take the cone full-wall as our new official set. 


\section{Experimental Results}

While the Cylinder test data is best for deriving wall angles, we have also located parts of the K271 cylinder framing camera series, which was fired in 1962-1963 by Howard Hornig but never published. Figure 2 is from this set. These were $152 \mathrm{~mm}$-long, $25.4 \mathrm{~mm}$ radius (1-inch diameter) LX-04 (85\% $\mathrm{HMX} / 15 \%$ Viton A) shots in various metal cylinders, driven by a Comp B booster and P-22 baratol/TNT plane wave lens. A grid was inscribed on the cylinder surface to make analysis easier. The detonation was photographed with a framing camera at about $1 \mu$ s intervals. By digitizing the cylinder edges, we are able obtain the edge angles. These angles are not a good as those obtained by streak camera in the Cylinder test itself, but this series tried various metals and the result was that copper was picked as the winner, to be used in the Cylinder test ever after. The tube dimensions are listed in Table 4.

Table 4. Metals used in the framing camera shots.

\begin{tabular}{|c|c|c|c|c|}
\hline & & Outer & Inner & Wall \\
\hline Wall & Density, & Radius, & Radius, & Thickness, \\
\hline Metal & $\mathrm{g} / \mathrm{cm}^{3}$ & $\mathrm{~mm}$ & $\mathrm{~mm}$ & $\mathrm{~mm}$ \\
\hline Al & 2.7 & 20.03 & 12.71 & 7.32 \\
\hline $\mathrm{Cu}$ & 8.93 & 15.31 & 12.71 & 2.60 \\
\hline $\mathrm{Ni}$ & 8.9 & 15.33 & 12.71 & 2.61 \\
\hline $\mathrm{Pb}$ & 11.35 & 14.79 & 12.73 & 2.06 \\
\hline $\mathrm{Pb}-\mathrm{Bi}^{*}$ & 10.7 & 14.91 & 12.72 & 2.20 \\
\hline Steel & 7.9 & 15.62 & 12.71 & 2.90 \\
\hline Th & 11.72 & 14.76 & 12.71 & 2.06 \\
\hline $\mathrm{U}^{* *}$ & 18.68 & 14.29 & 12.64 & 1.65 \\
\hline \multicolumn{5}{|c|}{$* 60$ volume fraction lead $* *$ depleted } \\
\hline
\end{tabular}

Some framing camera results for copper, nickel and aluminum are shown in Figure 3. About six coordinates are taken on each frame and the differential angle is obtained using Eq. (5). Points can blow upward at the left because the gas starts breaking out of the short cylinders and it folds back the ends, but we do not include these. The right side is the end-of-detonation end, and it rises to a near-constant value. The data cannot be taken more than 1-2 $\mu$ s after complete blow-out at the back end before the angles deform often to large values. The results are shown in Table 5 along with the standard full wall cone obtained from the Cylinder test. The spread is so large that all the metals effectively show the same result. 


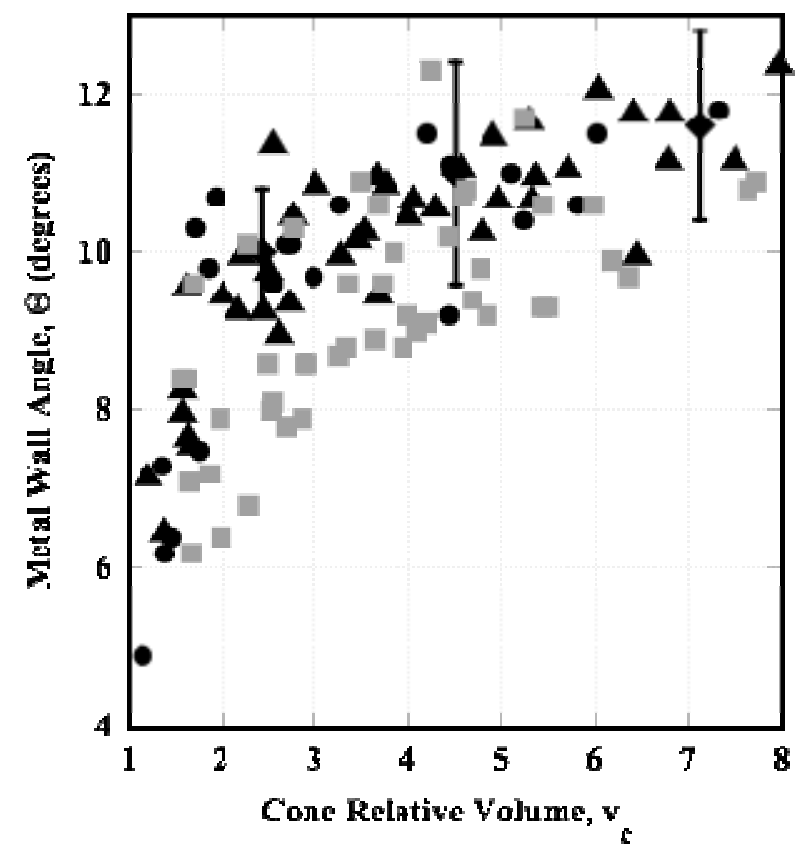

Figure 3. Framing camera edge angles from copper (triangles), nickel (circles) and aluminum (gray squares) cylinder shots. The full wall results from the Cylinder tests are the diamonds with error bars.

Table 5. Average wall angles for various metals from the framing camera study, listed according to the three standard cone relative volumes. The copper standard is the full wall cone result from above.

\begin{tabular}{|l|c|c|c|c|c|c|}
\hline & \multicolumn{3}{|c|}{ Wall Angle, degrees } & \multicolumn{3}{|c|}{ Error, degrees } \\
\cline { 2 - 7 } $\mathrm{v}$ & 2.4 & 4.4 & 7.0 & 2.4 & 4.4 & 7.0 \\
\hline $\mathrm{Al}$ & 9 & 10.3 & 10.5 & 1 & 10.3 & 1.5 \\
\hline $\mathrm{Cu}$ std & 10.0 & 11.0 & 11.6 & 0.8 & 1.4 & 1.2 \\
\hline $\mathrm{Cu}$ & 10 & 10.8 & 11.5 & 1 & 1 & 1.5 \\
\hline $\mathrm{Ni}$ & 10.2 & 10.7 & 11.5 & 1 & 1 & 0.5 \\
\hline $\mathrm{Pb}$ & 9.2 & 11.3 & 12.5 & 1 & 1.5 & 1.5 \\
\hline $\mathrm{Pb}-\mathrm{Bi}$ & & 10.5 & 11 & & 0.5 & 1 \\
\hline steel & 11 & 12 & 13 & 1.5 & 1.2 & 2 \\
\hline $\mathrm{Th}$ & 12 & 12.5 & & 1 & 0.5 & \\
\hline $\mathrm{U}$ & 12 & 12 & 13 & 1.5 & 1.5 & 1 \\
\hline
\end{tabular}

\section{Experimental Summary}

We have seen that streak camera energies for half-wall are larger than those for full-wall, so the use of the velocity $\mathrm{u}_{\mathrm{m}}$ at $0^{\mathrm{o}}$ cannot be correct. It seems more likely that the use of the surface velocity 
perpendicular direction to the wall at angle $\Theta$ will be the true one. If we imagine the Gurney problem with a conical tube and instant lighting, the direction of expansion would be the perpendicular. If so, all full-wall velocities taken at different probe angles $\alpha$ should be the same if corrected to $\Theta$. Also, the half-wall energy densities should be the same as the full-wall if we correct for the wall angle. We therefore change Eq. (4), at each relative volume, to

$$
E_{d}=\left\{\rho_{m}\left(\frac{R+x}{R_{o} \cos \Theta}\right)^{2} \ln \left(\frac{R+x}{R}\right)+\frac{\rho_{o}}{4}\left(\frac{R+x}{R}\right)^{2}\right\}\left(u_{m}^{*}\right)^{2},
$$

where

$$
\begin{aligned}
& \left(u_{m}^{*}\right)^{2}=\left(u_{m} \cos \Theta\right)^{2}, \text { streak } \\
& \left(u_{m}^{*}\right)^{2}=\left[\frac{u_{f}}{\cos (\Theta-\alpha)}\right]^{2}, \text { laser }
\end{aligned}
$$

Note the cosines cancel in $(\mathrm{R}+\mathrm{x}) / \mathrm{R}$. This says that the measured wall velocities at the angle $\alpha$ are converted to the smaller velocities at the angle $\Theta$, where $\Theta$ is a function of the relative volume. Then, the old radius $\mathrm{R}$ is converted to the cone radius $(\mathrm{R}+\mathrm{x}) / \cos \Theta$. We should not need the empirical coefficient $\delta$.

The use of the cone radius means that Eq. (10) for $\mathrm{v}_{\mathrm{c}}$ becomes the new relative volume. All modern Cylinder tests are done with full-wall so that the full-wall cone should become the new standard.

The right side of Table 1 shows that use of Eq. (11) brings the half-wall and full-wall energy densities closer together although the half wall numbers still are higher.

\section{Code Model}

The main calculational tool is a 2-D ALE hydrocode, which is descended from CALE. In calculations, Lagrange zoning is used initially to ensure that the surfaces where measurement occurs have not had mass flow away from them and are well defined. To avoid zone tangling, Eulerian relaxation is applied away from the surfaces of measurement at later times. Normally, the code directly delivers the particle velocity of each zone in the $\mathrm{x}$ and $\mathrm{y}$ directions, but this is not directly measurable in the laboratory. We need a way of looking at the wall at any given angle.

We first modeled the Cylinder test with $1.765 \mathrm{~g} / \mathrm{cm}^{3}$ PETN in copper, the closest we have to a standard, using programmed burn at 4 zones $/ \mathrm{mm}$. The three relative volume points come after 3.6, 6.6 and 
$9.5 \mu$ s for the full-wall and 4.7, 8.7 and $12.4 \mu$ s for half-wall. The first point for the full-wall may still have wiggles in the velocity and require averaging. The relative volume contours, as determined by the code, show many wiggles and the shape is amenable to drawing either the geometric or the cone lines.

We turn next to the wall velocity measurement. The code establishes a line for the measurement from outside down to the initial metal surface with a given angle $\alpha$, which may be $0^{\circ}$. The code looks at the $\mathrm{x}$ and $y$ coordinates of the wall along the ray as a function of time, and then it differentiates them to get a wall velocity. The code calculates the ray-surface intercept $\mathrm{x}$ and $\mathrm{y}$ values by looping over the surface zones until it finds where the ray passes between zones. It then calculates the velocity "surfvel", $\mathrm{u}_{\alpha}$, on the ray. The earlier simple angular model noted that a fixed point on the cylinder wall bends outward at about the angle $\Theta / 2$ [8]. At $0^{\circ}$, the probe sees new zones with higher velocities moving into view. If $\alpha$ is large enough, new zones with lower velocities will appear. From Eqs. (6) and (8), it is clear why the streak camera velocities are always higher than the laser velocities which have finite $\alpha$.

We calculated the PETN surfvel wall velocity and wall angle at each of the three Cylinder test points and converted them into values along the perpendicular using $\cos (\Theta-\alpha)$. The JWL in Table 6 was constructed using full wall relative volumes and an average of all energy densities, which were 6.66, 7.67 and $8.06 \mathrm{~kJ} / \mathrm{cc}$. The JWL's were constructed so that the ratio of the $19 \mathrm{~mm}$ to the $6 \mathrm{~mm}$ energy density was maintained. The calculated and measured wall velocities for full and half-wall cylinders are shown in Figure 4. The solid lines are as-calculated at $\alpha$ and should be compared with the solid triangles, which are the data. The agreement is good for full-wall and close for the half-wall. The dashed lines are the calculated $\mathrm{u}_{\mathrm{m}} *$ for each probe angle. We expect these to be independent of the probe angle, and they are close. 


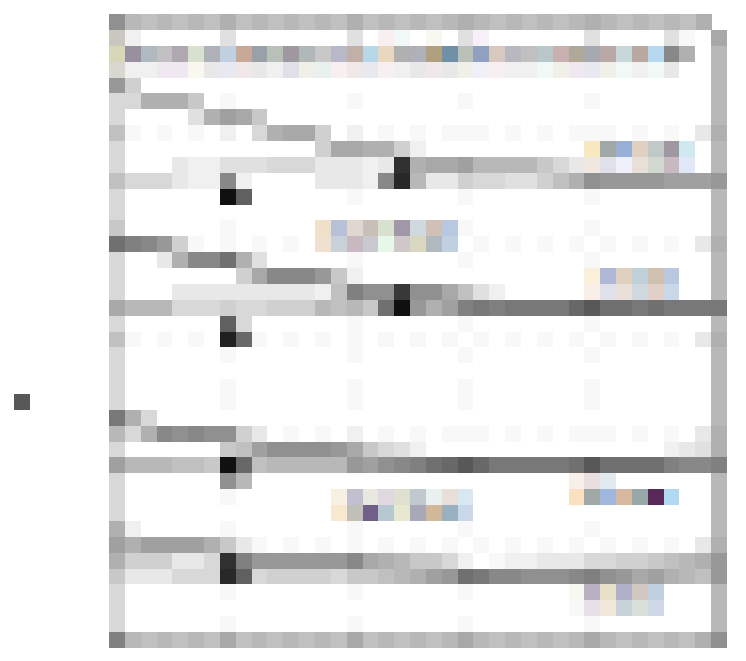

Figure 4. Calculated copper wall velocities for a dense PETN cylinder. Full-wall results are at the bottom and half-wall at the top. The black triangles are the measured values converted to $\mathrm{u}_{\mathrm{m}}{ }^{*}$. Solid lines are ascalculated from simulations and dashed lines are corrected to $\Theta$ togivẹ $u_{\mathrm{m}}$.

Table 6. JWL parameters for dense PETN, which is our best standard. GPa units are used.

\begin{tabular}{|c|c|}
\hline$\rho_{\mathrm{o}}$ & 1.765 \\
\hline$A$ & 729.5108 \\
\hline$B$ & 17.81760 \\
\hline $\mathrm{R}_{1}$ & 4.68 \\
\hline $\mathrm{R}_{2}$ & 1.32 \\
\hline$\omega$ & 0.31 \\
\hline $\mathrm{E}_{\mathrm{o}}$ & 10.50 \\
\hline$\Gamma_{\mathrm{cj}}+1$ & 3.79 \\
\hline $\mathrm{U}_{\mathrm{s}}$ & 8.285 \\
\hline $\mathrm{C}$ & 1.3071 \\
\hline $\mathrm{P}_{\mathrm{cj}}$ & 31.9363 \\
\hline
\end{tabular}




\section{Conclusions}

We have derived an analytic equation that predicts detonation energy densities suitable for code models without the need for empirical adjusting coefficients or standards. Also, the derivation of the relative volumes is now consistent with the energy density calculation. Finally, a correction for the position of the measuring probe is also present. This method brings half-wall data closer to full-wall without arbitary corrections, and the standard deviation of data sets dominated by streak cameras, has dropped from $\pm 3 \%$ to $\pm 2 \%$ or less. All PETN data agrees to $\pm 1.5 \%$. Further confirmation of accuracy to $\pm 1 \%$ comes from comparison of HMX data with historical JWL's, which were previously obtained by repetitive code fitting runs.

The work pushes the Cylinder test into realms where the data starts to break down. All the famous runs with dense PETN and various HMX's, which are largely represented by 40 -year-old streak camera data, should be repeated with modern laser methods.

\section{Symbols}

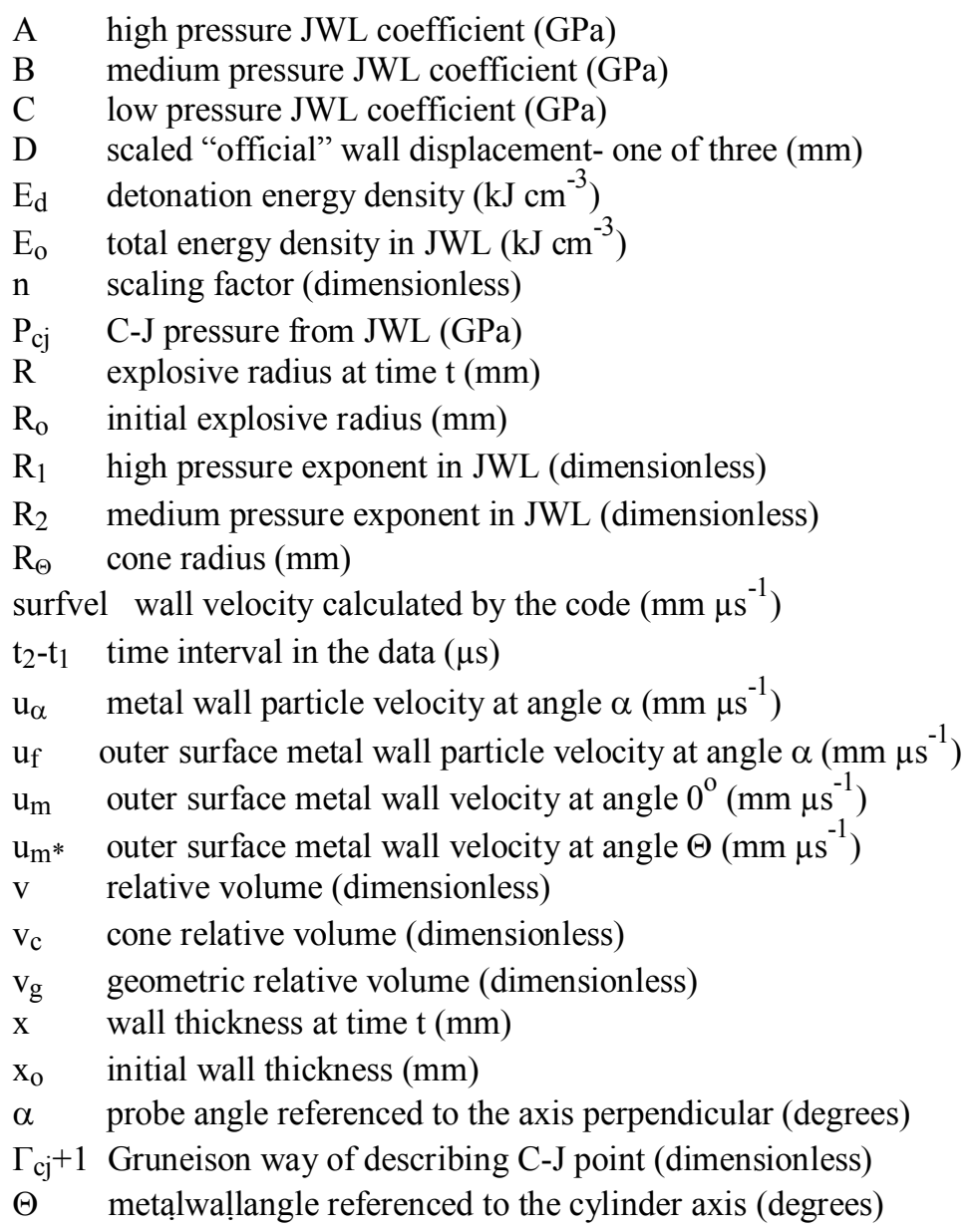


$\rho_{\mathrm{o}} \quad$ initial explosive density $\left(\mathrm{g} \mathrm{cm}^{-3}\right)$

$\rho_{\mathrm{m}} \quad$ initial metal wall density $\left(\mathrm{g} \mathrm{cm}^{-3}\right)$

$\omega \quad$ low pressure coefficient in JWL (dimensionsless)

\section{Acknowledgments}

This work performed under the auspices of the U.S. Department of Energy by Lawrence Livermore National Laboratory under Contract DE-AC52-07NA27344

\section{References}

[1] J. W. Kury, H. C. Hornig, E. L. Lee, J. L. McDonnel, D. L. Ornellas, M. Finger, F. M. Strange and M. L. Wilkens, "Metal Acceleration by Chemical Explosives," Proceedings Fourth Symposium (International) on Detonation, White Oak, MD, 1965, October 12-15, pp. 3-12.

[2] E. L. Lee, H. C. Hornig and J. W. Kury, Adiabatic Expansion of High Explosive Detonation Products, Lawrence Radiation Laboratory report UCRL-50422, 1968.

[3] P. C. Souers and J. W. Kury, "Comparison of Cylinder Data and Code Calculations for Homogeneous Explosives," Propellants, Explosives, Pyrotechnics, 1993, 18, 175-183.

[4] John E. Reaugh and P. Clark Souers, "A Constant-Density Gurney Approach to the Cylinder Test," Propellants, Explosives, Pyrotechnics, 2004, 29 [2], 124-128.

[5] R. W. Gurney, “The Initial Velocities of Fragments from Bombs, Shells and Grenades", Ballistic Research Laboratory, Aberdeen, MD, report BRL-405, 1943.

[6] P. W. Cooper, “Explosives Engineering”, Wiley VCH, New York, 1996, pp. 385-391.

[7] O. T. Strand, D. R. Goosman, C. Martinez and T. L. Whitworth, "Compact System for HighSpeed Velocimetry using Heterodyne Techniques,” Rev. Sci. Instr., 2006, 77, 083108.

[8] P. C. Souers and L. C. Haselman, Jr., "Detonation Equation of State at LLNL”, 1993, Lawrence Livermore National Laboratory Report UCRL-ID-116113, 1994.

\section{Acknowledgements}

This work performed under the auspices of the U.S. Department of Energy by Lawrence Livermore National Laboratory under Contract DE-AC52-07NA27344. 